\title{
Diyabet Hastaları için Arduino Kontrollü İnsülin Pompası Tasarımı
}

\author{
Mehmet Erhan ŞAHİN*1 \\ 1Isparta Uygulamalı Bilimler Üniversitesi, Teknik Bilimler Meslek Yüksekokulu, Biyomedikal Cihaz Teknolojileri \\ Bölümü, 32260, Isparta
}

(Alınış / Received: 11.12.2021, Kabul / Accepted: 3.02.2021)

Anahtar Kelimeler Mikrodenetleyici, Diyabet, İnsülin pompası
Özet: Diyabet, halk arasında şeker hastalığı olarak bilinen kandaki glukoz seviyesinin aşırı derece yükselmesiyle ortaya çıkan metabolik bir bozukluktur. Çevresel etkenlere bağlı olarak ve genellikle kalıtımsal olarak ortaya çıkmaktadır. Diyabetin çeşitli tipleri mevcuttur. Bu tiplerden Tip 1 diyabet insülin miktarının azalması sonucu ortaya çıkmaktadır. Bu hastaların tedavisinde vücuda insülin enjekte edilmesi gerekmektedir. Bunun için iğne tedavisinin yerini alan insülin pompası en önemli yeniliklerdendir. Bu çalışmada, bir mikrodenetleyici olan Arduino ile kontrollü sağlanan otomatik insülin pompası tasarlanmıştır. Hasta geliştirilen bu cihazı kullanarak kan şekeri değerinin normale yakın seviyede olması için vücuda enjekte edilmesi gereken insülin doz miktarını gerekli gördügü zamanlarda manuel veya programladığı zaman dilimlerinde otomatik olarak kolay bir şekilde uygulayabilmesi sağlanmış olacaktır.

\section{Design of Arduino Controlled Insulin Pump for Diabetes Patients}

\section{Keywords}

Microcontroler,

Diabet,

İnsulin Pump

\begin{abstract}
Diabetes is a metabolic disorder caused by the excessive increase of glucose level in the blood, which is known as diabetes mellitus. It occurs depending on environmental factors and generally inherited. There are various types of diabetes. Type 1 diabetes, one of these types, occurs as a result of a decrease in the amount of insulin. In the treatment of these patients, insulin should be injected into the body. For this, the insulin pump, which replaces needle therapy, is one of the most important innovations. In this study, an automatic insulin pump controlled by Arduino, a microcontroller, is designed. By using this device developed, the patient will be able to easily apply the amount of insulin dose that needs to be injected into the body in order to keep the blood glucose value close to normal, manually or automatically in the time periods programmed.
\end{abstract}

\section{Giriş}

Diyabet terimi Latince Diabetes mellitus (idrara geçen tatlı yada bal) olarak tanımlanır [1]. Diyabet kan şeker seviyesinin aşırı yükselmesi (hiperglisemi) sonucunda ortaya çıkan metabolik bir bozukluktur. Vücuttaki kan şekeri kimyasal ve hormonel yapı ile düzenlenir. Şeker metabolizmasının düzenlenmesinde pankreasın beta hücrelerinden salgılanan insülin hormonu büyük önem taşır. Yüksek kan şekerinin ortaya çıkması insülin cevabındaki bir bozukluk veya insülin salgllanmasındaki yetersizlik sonucunda olur [2].

Diyabetin akut belirtilerinin başında aşırı miktarda idrar üretimi gelir ve bunun nedeni hiperglisemidir. Susama ve sıvı tüketiminin artması ise idrar üretimini dengelemek içindir. Yorgunluk, enerji metobolizmasındaki değişiklikler, açıklanamayan kilo kayıpları, görme bozuklukları ise diyabetin diğer belirtileridir [3].

Günümüzde çeşitli diyabet türleri vardır. İnsüline bağımlı diyabet (Tip 1 diyabet), obeziteye bağlı diyabet (Tip 2 diyabet) en temel olanlarıdır [4]. Bunların dışında yaşlılık diyabeti (Tip 3), yetişkinlerde görülen gecikmiş otoimmün diyabet (Tip 1.5 diyabet), Gebeliğe bağlı diyabet (Gestasyonel diyabet) yer almaktadır [5,6].

Pankreasta bulunan beta hücrelerinin insülin üretmemesi sonucunda insülin yetersizliği olarak ortaya çıkan hastalık Tip 1 diyabettir. Bunun asıl nedeni de T-hücre aracılı otoimmün yanıttır 
[2]. Diyabet türleri çeşitli yöntemlerle kesin olmamakla birlikte tedavi edilebilmektedir. Tip 1 diyabetin en temel tedavi yöntemi; insülin kalemleri ya da insülin pompası yardımıyla vücuda insülin enjekte edilmesi ile kan şekerleri normal seviyede tutulmasıdır. İnsülin pompaları, belirli zaman dilimlerinde 24 saatte vücuda insülin enjekte edebilen cihazlardır. [7,8]. Tip 2 diyabettin tedavisi ise kan şekeri düşürücü ilaçlar ve insülin takviyesi ile yapılabilinmektedir. [9,10].

Kan şekeri seviyesinin normal değerleri ortalama 80$120 \mathrm{mg} / \mathrm{dl}$ ' dir. Diyabet hastalarının kan şekeri değerleri de bu seviyelerde olması sağlanmalıdır. Düşük kan şekeri (Hipoglisemi) yaşayan hastalarda en fazla 140-150 mg/dl değerlerinde olması gerektiği önerilmektedir. $400 \mathrm{mg} / \mathrm{dl}$ değerinin üzerindeki kan şekeri değerleri sık idrara çıkma sorunu yaratır, bu da aşırı su kaybına (dehidratasyon) neden olur. $600 \mathrm{mg} / \mathrm{dl}^{\prime} \mathrm{nin}$ üzerindeki değerler yaşamı tehdit etmese de genellikle tıbbi müdahale gerektirirler. Ancak bilinç kayıpları ve nöbetlere sebep olduğundan hipoglisemi acil olarak tedavi edilmelidir $[11,12]$.

1963 yılında Dr. Arnold Kadish tarafından prototip olarak bir insülin pompası tasarlanmıştır. Şekil 1'de olduğu gibi tasarlanan sistem sırt çantası șeklinde taşınmasından ve çok büyük olmasından dolayı çok kullanışlı değildi [13].

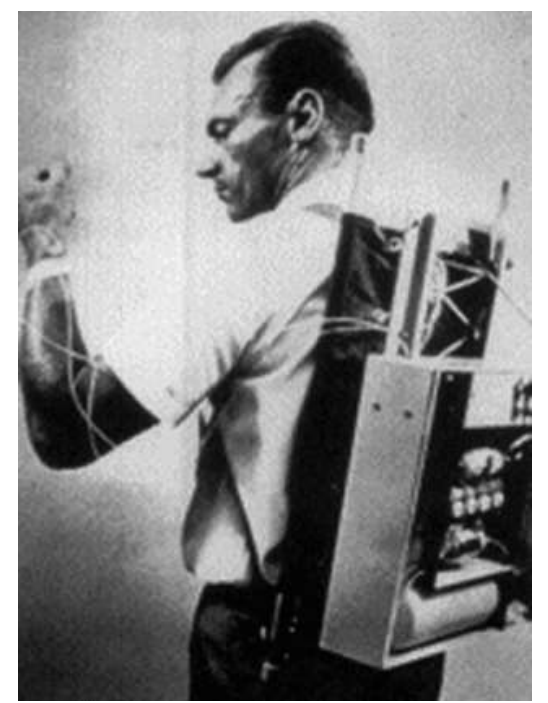

Şekil 1. Sırtta taşınan ilk infüzyon pompası [13]

İlk giyilebilir insülin pompasını 1973 yılında Dean Kamen icat etmiştir. 1974 yllına gelindiğinde Dr. Ernst Friedrich sürekli glukoz takibi yapabilen Biostator isimli insülin pompasını geliştirmiștir. Bu insülin pompası öncekilere göre bilgisayar denetimli kapalı döngü olarak çalışmasından ve pankreas hücrelerinin fonksiyonunu taklit etmesinden dolayı biraz daha ilgi görmüştür. AutoSyringe firması 1976 yılında Dean Kamen tarafından icat edilen insülin pompalarını üretmeye başlamıştır. Teknolojik gelişmeler sayesinde 1990'lı yıllarda öncekiler göre daha küçük yeni nesil kişisel bilgisayar arayüzleri ve alarmlar gibi özellikleri bulunan insülin pompaları üretilmeye başlanmıştır. 2003 yılında doz ayarı, otomatik kan şekeri değeri ölçebilen özellikler eklenerek yeni cihazlar piyasaya sürülmüştür $[14,15,16]$.

Yapılan çalışmalarda perfüzyon pompaları üzerine çalışmalar yapılmıştır. Bir başka çalışmada pompa için kontrol sistemleri geliştirilmiş çeşitli kontrol yapıları karşılaştırılmıştır. $\mathrm{Bu}$ çalışmada diyabet hastalarının kan șekerlerinin düzenlenmesi, normal seviyede tutulabilmesi için gün içinde vücutlarına enjekte edecekleri gerekli insülinin manuel ya da otomatik olarak ayarlanan miktarlarda vücuda enjekte edebilmelerini sağlayan insülin pompası cihazı tasarımı gerçekleștirilmiştir.

\section{Tasarlanan İnsülin Pompası}

Prototip olarak geliştirilen insülin pompası 3D printer kullanılarak tasarlanmıştır. Şekil 2' de olduğu gibi tasarlanan insülin pompası ön yüzünden bakıldığında dokunmatik ekran yer almaktadır. Kasa içerisinde ise işleyişi kontrol edecek olan Arduino mikrodenetleyicisi, insülin enjeksiyonu için step motor, belirli miktarda insülin depolanması için rezervuar ve enerji sağlamak için bataryadan oluşmaktadır. Birde insülinin vücuda iletilebilmesi için kullanılacak esnek bir tüp olan kanülden oluşmaktadır.

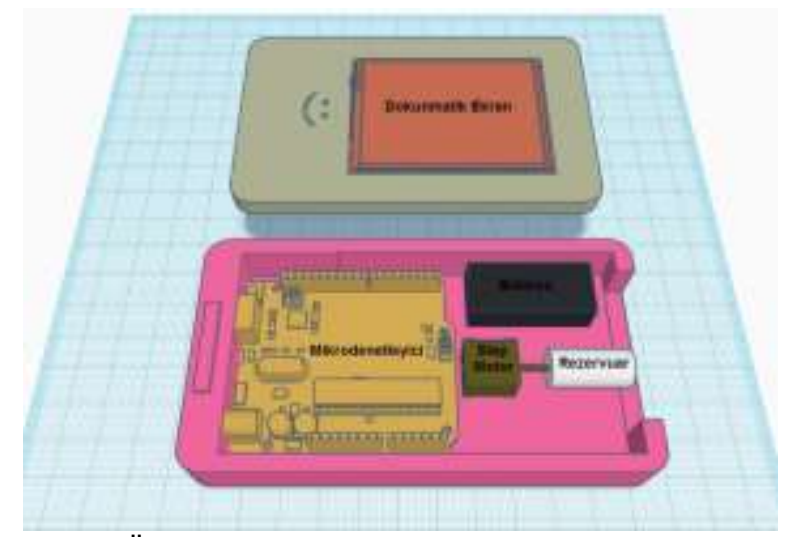

Şekil 2. Üç boyutlu tasarım görüntüsü

Dokunmatik TFT ekran üzerinden tarih, saat, hazıfa, ayarlar, manuel ve otomatik mod menüleri yer almaktadır. Manuel mod menüsü altında hasta gün içerisinde istediği bir zamanda vücuduna enjekte etmek istediği insülin doz miktarını belirleyebilmektedir. Belirlenen bu doz kanül içerisindeki boşluk alındıktan sonra otomatik olarak enjeksiyon gerçekleştirebilmektedir. Ayrıca burada kanül içerisindeki hava boşluğunu da manuel olarak alabilmektedir. Otomatik mod menüsü altında hasta gün içerisinde istediği zaman dilimlerini belirleyerek istediği insülin doz miktarını belirleyerek kayıt edebilmektedir. Bu ayarlar yapıldıktan sonra cihaz otomatik olarak gün içerisinde enjeksiyonu kendisi uygulayacaktır. Uygulamadan önce kanül içerisindeki boşluk otomatik olarak alınacaktır. Hafıza menüsü 
altında daha önce otomatik mod menüsünde girilmiş olan doz miktarları görülebilmektedir. Ayarlar menüsünden boy kilo bilgileri girilerek doz ayarlaması, saat ve tarih ayarları yapılabilmektedir.

\subsection{Arduino}

Tasarlanan insülin pompasının çalışmasını kontrol edebilmek için mikrodenetleyici olarak Arduino Uno kullanılmıştır. Arduino fiziksel programlama kartlarıdır. Giriş/Çıkış kartı ve Processing/Wiring dilinin bir uygulamasını içerir. Arduino kartlarında mikrodenetleyici olarak Atmel AVR bulunur. Bu kartlara program yükleyebilmek ve diğer devre elemanları ile bağlantı yapabilmek için çevresel elemanlardan oluşurlar. Arduino kartları 5 Volt, 16 MHz kristal osilatör ile çalışırlar. Arduino üzerinde bulunan mikrodenetleyici içerisinde bootloder programı yazılı olduğundan başka bir programlayıcı gerekmez.

\subsection{Step Motor}

Step motorlar dönme hareketi ile elektrik enerjisini mekanik enerjiye çeviren elektromekanik cihazlardır. Step motorların girişlerine pals sinyal uygulanırsa analog olarak dönme hareketi gerçekleştirirler. Bu dönme hareketini hassas bir şekilde ve adım adım yaparlar. Yapıları sabit miknatıs kutuplu motor şeklindedir.

$360^{\circ}$ dönen bir step motorlarda gerekli adım açısı (Qs) Denklem 1' deki gibi bulunur. Burada Ns; stator kutup sayısını, Nr; rotor faz sayısını göstermektedir.

$$
Q_{s}=\frac{\left|N_{r}-N_{s}\right|}{N_{r} \cdot N_{s}} \cdot 360^{\circ}
$$

Step motorun adım sayısı (S) Denklem 2' de gösterildiği gibi bir adımın açısı (Qs) ile bulunabilir.

$$
S=\frac{360^{0}}{Q_{s}}
$$

İnsülin enjektesi için pompa hareket kontrolünü sağlamak için Şekil 3' de gösterildiği gibi devir başına 200 adım, $1.8^{\circ}$ lik adım açısına sahip milli $3.9 \mathrm{~V}$ gerilimle çalışan step motor kullanılmıştır. Şekil 4' de devre modeli verilen step motoru kontrol edebilmek için ULN2003 step motor sürücüsü kullanılmıştır.

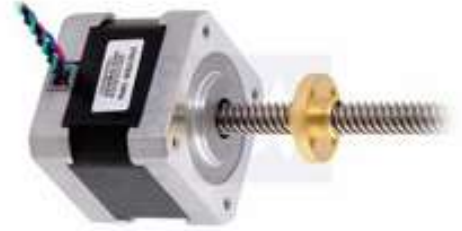

Şekil 3. Step Motor - PL-2690

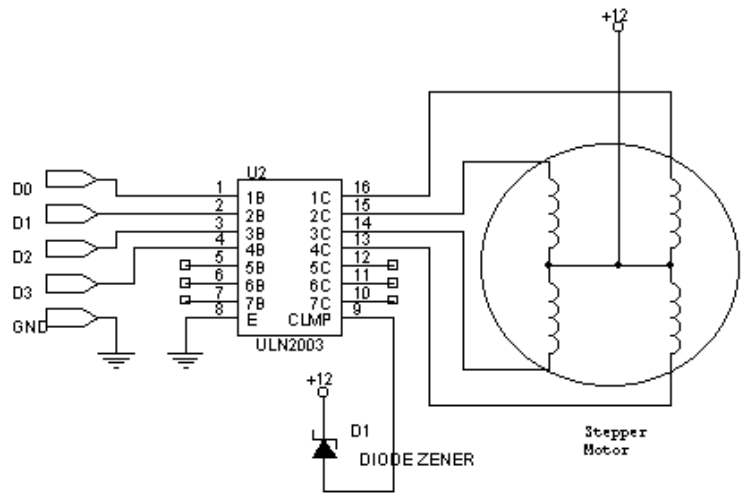

Şekil 4. ULN2003 ile Step Motor Kontrol Devresi

\subsection{Dokunmatik Ekran}

İnsülin miktarını ayarlamak, gerekli veri girișini yapabilmek ve daha önce enjekte edilen miktarları görebilmek için Arduino Uno uyumlu, $3.3 \mathrm{~V}$ ve $5 \mathrm{~V}$ ile çalışabilen, TFT sürücüsü entegresi 8 bit data ve 4 bit kontrol arabirimine sahip 2.4" dokunmatik TFT LCD ekran kullanılmıștır (Şekil 5).

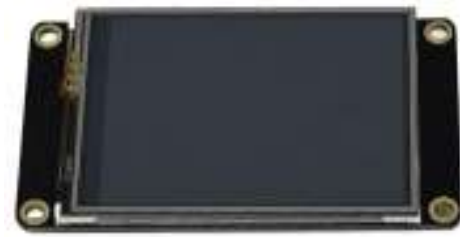

Şekil 5. 2.4" Dokunmatik TFT LCD ekran

\section{3. İnsülin Miktarının Hesaplanması}

İnsülinin bulunduğu rezervuar kısmındaki miktarın hasta vücuduna enjekte edebilmek için doz miktarının hesaplanması gerekmektedir. Çünkü kişi enjektördeki miktarı analog olarak görebilmektedir. Bunun için Arduino bu analog bilgiyi elektriksel bilgiye dönüştürerek step motora bilgi göndererek adım miktarının belirlenebilmesi gerekmektedir. Böylece vücuda enjekte edilecek insülin miktarı belirlenebilir.

Farklı miktarlarda ve șekillerde insülin rezervuarları mevcuttur. Toplam doz miktarı $3 \mathrm{ml}, 300$ ünite olan silindirik bir rezervuar kullanılmıștır. İlk olarak rezervuarın kesit alanı Denklem 3' de olduğu hesaplanabilir. 


$$
S=\pi x r^{2}=3,14 x(6 \mathrm{~mm})^{2}=113,04 \mathrm{~mm}^{2}
$$

Step motor ucunda bulunan milin bir adımlık ilerleme mesafesi (a) 0,7mm 'dir. Buradan milin bir tam tur sonucunda insülin hacmi (V) bulunabilir.

$$
V=S x \mathrm{a}=113,04 \mathrm{~mm}^{2} x 0,7 \mathrm{~mm}=79,12 \mathrm{~mm}^{3}
$$

Hasta cihaz üzerindeki menüden insülin miktarını 0,1 ünite $\mathrm{kg}$ /gün olacak hassasiyette ayarlayabilmesi için milin bir tam turunda $79,12 \mathrm{~mm}^{3}$ oda yaklașık olarak 8 ünite $\mathrm{kg}$ /gün olursa step motor 4,50'lik bir dönme hareketi gerçekleştirir. Kullanmış olduğumuz step motorun bir adım açısı 1,8 ' dir. 0.1 ünite kg/gün' lük step motor dönüş (DS) sayısı Denklem 5’ de gösterildiği bulunabilir.

$$
D S=\frac{4.5^{\circ}}{1,8^{\circ}}=2.5 \mathrm{adlm}
$$

Hastanın belirlemiş olduğu insülin doz miktarı (DM) için motorun dönüş adım sayısı (T) Denklem 6' deki formül ile hesaplanmaktadır.

$$
T=\frac{2.5 \mathrm{adlm} \times D M(U)}{0,1(U)}(\mathrm{adlm})
$$

\section{Tartışma ve Sonuç}

Sağlıklı kișilerdeki pankreasın insülin salınımı yapay olarak yerine getiren cihazlar insülin pompalarıdır. İnsülin hastalarının dünya genelinde yaklașık 450 bini insülin pompası kullanmaktadır. İnsülin pompası; hastaların HbA1c değerlerinde insülin kalemleri ya da insülin enjeksiyonuna göre daha iyi sonuç verdiği kullanıcılar tarafindan belirtilmektedir. Ayrica insülin kalem tedavisinde enjekte edilen insülin doz miktarına göre gıda alınırken, insülin pompasında alınan gıdaya göre insülin enjekte edilmektedir. İnsülin pompasının kullanımının bir diğer faydası da oluşabilecek ani şeker düşüklüklerini önlemesidir. İnsülin pompası, hastalık, stres, egzersiz, yeme alışkanlıkları durumlarına göre insülin kontrolünde kolaylık sağladığından hastaların yaşam kalitesini ciddi oranda arttırmaktadır. Burada geçekleştirilen tasarımla yerli üretime kapı açılmış olmaktadır. Mevcut ürünler yurtdışından ithal edilmektedir ve fiyatları 600TL' den bașlayıp 18.000TL' ye kadar çıkmaktadır. Artı sarf malzeme giderleri eklenmektedir. Kur farklılıklarına göre bu fiyatlar değişkenlik göstermektedir. SGK ödemeleri mevcut olmasına rağmen hastalar fark ödemektedir. $\mathrm{Bu}$ farklarda yaklaşık 5000TL civarındadır. Yerli üretim ile maliyetlerinin düşük olmasından birçok hastanın kolaylıkla insülin pompasına ulaşması sağlanmış olacaktır. Ayrıca devlet destekli satın almalarda ithalata harcanan miktar azalmıș olacaktır. Bundan sonraki çalışmalarda akıllı saatler ve telefonlar ile entegrasyonun gerçekleştirilmesi ve daha küçük boyutlara getirilmesi planlanmaktadır.

\section{Kaynakça}

[1] Tierney, L. M., McPhee, S. J., Papadakis, M. A. 2002. Current medical Diagnosis \& Treatment. International edition. Lange Medical Books. McGraw-Hill. 1203-1215.

[2] Rother, K.I. 2007. Diyabetes Treatment Bridging the Divide. N England Journal Med. 1499-1501.

[3] Eberhart, M.S., Ogden, C., Engelgau, M., Cadwell, B., Hedley, A.A., Saydah, S.H., 2004. Prevalence of Overweight and Obesity Among Adults with Diagnosed Diyabetes. United States. Morbidity and Mortality Weekly Report. 53(45). Centers for Disease Control and Prevention. ss. 10661068 .

[4] WHO. 1999. Definition, Diagnosis and Classification of Diyabetes Mellitus and its Complications. World Human Organization Department of Noncommunicable Disease Surveillance. Geneva https://web.archive.org/web/20150528114046 /http://whqlibdoc.who.int/hq/1999/who_ncd_ ncs_99.2.pdf (Erişim Tarihi: 11.11.2020).

[5] Lang, I. A., Galloway, T. S., Scarlett, A., Henley, W. E., Depledge, M., Wallace, R. B., Melzer, D., 2008. Association of Urinary Bisphenol A Concentration with Medical Disorders and Laboratory Abnormalities in Adults. Journal of the American Medical Association. 300.

[6] Borch-Johnsen, K., Joner, G., Mandrup-Poulsen, T., Christy, M., Zachau-Christiansen, B., Kastrup, K., Nerup, J., 1984. Relation between breastfeeding and incidence rates of insulin-dependent diyabetes mellitus.

A hypothesis. Lancet. 2 (8411). ss. 1083-6.

[7] Virtanen, S., Knip, M., 2003. Nutritional risk predictors of beta cell autoimmunity and type 1 diyabetes at a young age. Am J Clin Nutr. 78 (6). ss. 1053-67.

[8] Gerstein, H., Yusuf, S., Bosch, J., Pogue, J., Sheridan, P., Dinccag, N., Hanefeld, M., Hoogwerf, B., Laakso, M., Mohan, V., Shaw, J., Zinman, B., Holman, R., 2006. Effect of rosiglitazone on the frequency of diyabetes in patients with impaired glucose tolerance or impaired fasting glucose: a randomised controlled trial. Lancet. 368 (9541). Ss. 1096-105

[9] Vinik, A.I., Fishwick, D.T., Pittenger G. 2004. Advances in diyabetes for the millennium toward a cure for diyabetes. MedGenMed : Medscape general medicine. 12s.

[10] Cohen, R.V., Schiavon, C.A., Pinheiro, J.S., Correa, J.L., Rubino, F. 2007. Duodenal-jejunal bypass for the treatment of type 2 diyabetes in patients with body mass index of $22-34 \mathrm{~kg} / \mathrm{m} 2$ : a report of 2 cases. Surg Obes Relat Dis. 195-197s.

[11] Diyabet. http://tr.vikipedia.org/wiki/Diyabet\#Tip_1_diy abet (Erişim Tarihi: 11.11.2020). 
[12] Abacl, 2007. Tip 1 Diyabetli Adolesanslarda İnsülin İnfizyon Pompa Uygulamasının Klinik ve Metabolik Paremetreler Üzerine Etkisi. Uzmanlık Tezi. İzmir.

[13] Alsaleh, F. M., Smith, F. J., Keady, S., Taylor K. M. G. 2020. Insulin Pump: from inception to the present and toward the future. Journal of Clinical Pharmacy and Therapeutics. Volume:35, Issue:2,127-138 https://doi.org/10.1111/j.13652710.2009.01048.x

[14] Kesavadev, J., Saboo, B., Krishna, M.B. et al. 2020. Evolution of Insulin Delivery Devices: From Syringes, Pens, and Pumps to DIY Artificial Pancreas. Diabetes Ther 11, 1251-1269. https://doi.org/10.1007/s13300-020-00831-z

[15] Bode BW, Sabbah HT, Gross TM, Fredrickson LP, Davidson PC. 2002. Diabetes management in the new millennium using insulin pump therapy. Diabetes Metab Res Rev 2002;18: S14-S20.

[16] Tamborlane WV, Sherwin RS, Genel M, Felig P. Reduction to normal of plasma glucose in juvenile diabetes by subcutaneous administration of insulin with a portable infusion pump. N Engl J Med 1979;300:573-578. 